\title{
Trabectedin: the evidence for its place in therapy in the treatment of soft tissue sarcoma
}

This article was published in the following Dove Press journal:

Core Evidence

20 August 2009

Number of times this article has been viewed

\author{
Katherine A Thornton \\ Sidney Kimmel Comprehensive \\ Cancer Center at The Johns Hopkins \\ University, Baltimore, MD, USA
}

Introduction: Soft tissue sarcoma accounts for less than $1 \%$ of all malignant neoplasms and is comprised of a very heterogeneous group of tumors with over 50 different subtypes. Due to its diversity and rarity, developing new therapeutics has been difficult, at best. The standard of care in the treatment of advanced and metastatic disease over the last 30 years has been doxorubicin and ifosfamide, either alone or in combination. There has been significant focus on developing new therapeutics to treat primary and metastatic disease. Trabectedin (ecteinascidin-743) is a tetrahydroisoquinoline alkaloid which has been evaluated in the treatment of metastatic soft tissue sarcoma.

Aims: To review the current evidence for the therapeutic use of trabectedin in patients with soft tissue sarcoma.

Evidence review: Five phase I studies in patients with solid tumors, all of which include sarcoma patients, evaluating the dosing and toxicity of trabectedin were performed with efficacy being evaluated as a secondary endpoint. Additionally, there are four phase I trials evaluating trabectedin in combination with frontline therapeutic drugs in soft tissue sarcoma. Four phase II studies were performed in soft-tissue sarcoma patients with objective response rates ranging from $3.7 \%$ to $17.1 \%$. Additionally, in two compassionate use trials, objective response rates between $14 \%$ and $51 \%$ were seen, the largest response resulting from a study specifically focusing on liposarcoma.

Place in therapy: Trabectedin is a potential therapeutic option for the management of softtissue sarcoma. It appears to have specific activity in a select group of histologies, most notably myxoid/round cell liposarcoma. Although it would be helpful to study the use of trabectedin in a randomized, controlled fashion, the relative rarity of soft-tissue sarcoma, and heterogeneity of the histologic subtypes, makes phase III trials a difficult prospect.

Keywords: soft tissue sarcoma, metastatic, trabectedin, ET-743, Yondelis ${ }^{\circledR}$

Core evidence proof of concept summary for trabectedin in soft-tissue sarcoma

\begin{tabular}{|c|c|}
\hline Outcome measure & Emerging evidence \\
\hline Efficacy & $\begin{array}{l}\text { Potential use as monotherapy or combination therapy in patients } \\
\text { with soft-tissue sarcoma, either as first line therapy or in patients who } \\
\text { have failed or proven refractory to other cytotoxic chemotherapies. }\end{array}$ \\
\hline Response rates & $\begin{array}{l}\text { Objective response rates ranging from } 3.7 \% \text { to } 17.1 \% \text {, with stable } \\
\text { disease rates reported to }>6 \text { months. }\end{array}$ \\
\hline Tolerability & $\begin{array}{l}\text { Most commonly utilized dose, and maximum tolerated dose } \\
\text { in several phase I trials is } 1.5 \mathrm{mg} / \mathrm{m}^{2} \text { as a } 24 \text {-hour continuous } \\
\text { intravenous infusion every } 2 \mathrm{I} \text { days, although other shorter infusion } \\
\text { schedules have been utilized as well. }\end{array}$ \\
\hline
\end{tabular}

(Continued)
Correspondence: Katherine A Thornton Sidney Kimmel Comprehensive Cancer Center at The Johns Hopkins University, Baltimore, MD, USA

Email kthornt2@jhmi.edu 


\begin{tabular}{|ll|}
\hline (Continued $)$ & \\
\hline Outcome measure & Emerging evidence \\
\hline Safety & $\begin{array}{l}\text { Generally, well tolerated with noncumulative, reversible, and manageable } \\
\text { adverse events including neutropenia, nausea and vomiting, and elevated } \\
\text { transaminases. Rhabdomyolysis and acute renal failure were observed } \\
\text { in a few notable cases. }\end{array}$ \\
\hline
\end{tabular}

\section{Scope, aims, and objectives}

Adult soft tissue sarcomas (STS) are a heterogeneous group of malignant tumors arising from the embryonal mesenchymal tissue layers which account for less than $1 \%$ of all malignant neoplasms. There are approximately 10,000 new STSs diagnosed every year in the United States and over $47 \%$ percent of those patients will die from their disease.

Only two anticancer treatments to date, doxorubicin and ifosfamide, have consistently shown single-agent activity in this heterogeneous disease group with responses in the $10 \%-20 \%$ range as single agents and up to $40 \%$ in combination. Trabectedin, formerly known as ecteinascidin-743 (ET-743), is a natural marine compound derived from the Caribbean tunicate Ecteinascidia turbinata. Trabectedin is currently approved for the treatment of STS in Europe but has not yet been approved in the United States. The objective of this article is to present an overview of current therapeutic options in STS and to review the current evidence for the therapeutic potential of trabectedin in this disease group.

\section{Methods}

A literature search was conducted on January 4, 2009 in the following databases using the search terms 'trabectedin', 'ET-743', or 'Yondelis ${ }^{\circledR}$ and sarcoma'. The cut-off date was from the beginning of the database to the date of the search unless otherwise stated. Searches were completed in PubMed from 1966 to date, search strategy 'trabectedin and sarcoma' limited to English language results only; in EMBASE from 1970 to date, search strategy 'trabectedin and sarcoma' limited to English and human studies.

A total of 57 records were identified in PubMed. Records were manually reviewed and any animal studies, in vitro studies, case studies, general narrative reviews, and articles focusing on other entities which mentioned trabectedin were excluded. The remaining 13 records were included.

A total of 112 records were identified in EMBASE. Records were manually reviewed and again, any animal studies, in vitro studies, case studies, general narrative reviews, and articles focusing on other entities which mentioned trabectedin were excluded. Any articles which were included in the PubMed data search were excluded. The remaining four records were included.

The identified studies were then classified into five classes of evidence based on the design of the study, with level 1 evidence presenting the strongest evidence and level five representing the weakest evidence, as indicated in Table 1. No systematic reviews or meta-analyses were identified. Publications relating to the pharmacoeconomic evidence of trabectedin were not identified.

\section{Disease overview}

Approximately 10,000 new cases of STS are diagnosed annually in the United States, ${ }^{1}$ and fewer than $50 \%$ of patients will receive curative treatment with the currently available treatment modalities. Accounting for approximately 1\% of all adult malignancies, STS comprise a heterogeneous group of malignancies that arise from the connective tissues. While sarcomas can arise virtually anywhere, the most common primary site is the extremities. This is followed by the retroperitoneum, torso, and head and neck. ${ }^{2}$ There are over 50 different subtypes of STS, and the World Health Organization (WHO) classifies most STS according to the presumptive tissue of origin. ${ }^{3}$ This, along with the overall rarity of the disease, account for the difficulty in conducting large randomized clinical trials.

STS tend to metastasize early via a hematogenous route, with a predilection for the lungs and less frequently the liver and bone. Lymphangitic spread is uncommon $(<3 \%)$, except for certain histologic types such as rhabdomyosarcomas, epithelioid sarcomas, and angiosarcomas. ${ }^{4,5}$ About $10 \%$ of patients present with metastatic disease, and although the majority of patients will present with a clinically localized tumor, $30 \%-60 \%$ will eventually develop a local recurrence or metastatic disease. ${ }^{6,7}$ This percentage increases up to $70 \%$ for patients with high-grade STS. ${ }^{8}$

Analysis of the distribution of primary histology and grade demonstrates that among patients that develop lung metastases, leiomyosarcoma (LMS) is most common, followed by undifferentiated pleomorphic high grade sarcoma, liposarcoma, and synovial sarcoma. The incidence 
of pulmonary metastases within each histologic group correlates with the incidence of high-grade lesions within that group. ${ }^{9}$

The development of metastatic disease poses a major clinical problem as it is seldom amenable to a curative treatment. The efficacy of conventional chemotherapy is limited with response rates of $10 \%-40 \%$ for single agent or combination therapy. ${ }^{10,11}$

\section{Current therapy options}

Surgical resection with wide margins, with or without radiation therapy, remains the standard of care for localized disease with continued debate when deciding upon the use of adjuvant chemotherapeutic treatment options. ${ }^{12}$ Doxorubicin and ifosfamide have been used both as single agents and as combination therapy and remains the mainstay of treatment in most histologies of STS. Recently, gemcitabine and docetaxel have proven efficacious in the treatment of LMS and undifferentiated pleomorphic high grade sarcoma, and have been increasingly used as a first line regimen in these histologic subtypes. ${ }^{11}$ Investigators have evaluated the use of pegylated liposomal doxorubicin (PLD) in several phase II clinical trials, trying to capture the efficacy of doxorubicin while minimizing the side effects like cardiac toxicity and myelosuppression. ${ }^{13,14}$ The results of the studies evaluating PLD have never matched those of its parent drug, but with a safer side effect profile, in certain circumstances, it is preferable. The taxanes, along with PLD, have been specifically evaluated in angiosarcomas, and are often used as first-line drugs in this particular histologic subtype. ${ }^{15}$

Given the relative rarity of STS, along with the heterogeneity of the sarcoma subtypes, it has been difficult to perform meaningful studies to evaluate drug efficacy. A retrospective study performed by the European Organization for Research and Treatment of Cancer (EORTC) soft tissue and bone sarcoma group demonstrated that only $8 \%$ of patients with advanced or metastatic disease treated with a doxorubicin-based regimen are alive at five years. ${ }^{8}$ Furthermore, the toxicity encountered with the use of doxorubicin and/or high-dose ifosfamide, often times limits their use as palliative chemotherapeutic options, which unfortunately is what is often needed most in the advanced disease setting.

Trabectedin (Yondelis ${ }^{\circledR}$, Pharma Mar, Madrid, Spain), was originally a natural product derived from the Caribbean marine tunicate Ecteinascidia turbinata. The current supply is based on a semi-synthetic process. ${ }^{16}$ It is a tetrahydroisoquinoline alkaloid that binds to the minor groove of DNA and selectively inhibits DNA transcription ${ }^{17}$ and assembly of the microtubular cytoskeleton. ${ }^{17,18}$ At the cellular level, trabectedin blocks cell cycle progression in the G2/M phase through a p-53-independent apoptotic process which effectively inhibits transcriptional activation of inducible genes. ${ }^{19}$

\section{Clinical evidence for the use of trabectedin in the treatment of STS Phase I studies of trabectedin \\ as a single agent}

Phase I studies have evaluated a variety of dosing schedules. A phase I trial and compassionate use trial used a 24-hour continuous infusion schedule in 29 pretreated, advanced soft-tissue sarcomas and bone sarcomas. The study demonstrated disease response in fibrosarcoma, liposarcoma and osteosarcoma, with a recommended dose of $1.5 \mathrm{mg} / \mathrm{m}^{2} .^{20,21}$ A phase I pharmacokinetic trial using the same infusion schedule in patients with solid tumors enrolled 14 sarcoma patients, in which nine were treated at the recommended dose. Two of the partial disease responses in this trial included an osteosarcoma and a liposarcoma patient. ${ }^{21}$ A phase I and pharmacokinetic study of trabectedin was performed in children with refractory tumors in a Children's Oncology Group study. Twelve evaluable patients were followed to establish a pediatric dose with a recommended phase II dose of $1.1 \mathrm{mg} / \mathrm{m}^{2}$ administered as a 3 hour IV infusion. One child with Ewing's sarcoma experienced a complete response. This patient had complete resolution of pulmonary metastases and remained on therapy for a total of 16 courses. The most common toxicity was reversible hepatic toxicity which occurred in $58 \%$ of patients. ${ }^{22} \mathrm{~A}$ phase I and pharmacokinetic study was performed using a one- or three-hour intravenous (IV) infusion every 21 days in patients with solid tumors in a total of 72 patients, including three gastrointestinal stromal tumor patients and three uterine sarcomas. Forty-nine patients were evaluable for tumor response at the end of the trial $(68 \%)$ with two objective tumor responses (one complete response $[\mathrm{CR}]$ and one partial response [PR]), both observed in the three-hour infusion cohort. Both objective responses were in sarcoma patients, the first, a uterine LMS patient who received 10 cycles of trabectedin at a dose of $1.5 \mathrm{mg} / \mathrm{m}^{2}$ and had a CR of 18 weeks duration. The PR was observed in a stromal sarcoma of the colon, who received 17 cycles of treatment and after cycle 13, had a PR of six months duration. A third patient with gastric stromal sarcoma, who did not meet RECIST criteria for PR, achieved a 37\% reduction 
in tumor size and stable disease for 20 weeks. The most frequently encountered non-hematologic toxicities were nausea, vomiting, fatigue and increased liver transaminases. Grade 3 and 4 neutropenia and thrombocytopenia were observed at the highest dose level with the one-hour infusion and at the $1.3 \mathrm{mg} / \mathrm{m}^{2}$ dose level with the three-hour infusion. ${ }^{23}$ A daily five day schedule was evaluated in a phase I study that included 42 patients. Three patients on this study had discernable antitumor activity, one of which was a uterine LMS patient, who experienced a $41 \%$ reduction in lung metastases and a $27 \%$ overall tumor response after four courses of $325 \mu \mathrm{g} / \mathrm{m}^{2} /$ day. $^{24}$

\section{Combination phase I studies of trabectedin}

Several phase I studies in solid tumor patients including sarcoma patients were performed with trabectedin, in combination with other cytotoxic chemotherapies, with the idea of expanding on the encouraging sarcoma responses seen in the earlier phase I single-agent studies. These studies were also prompted by in vitro studies showing synergy between trabectedin and cisplatin and trabectedin and doxorubicin, specifically in STS cells. ${ }^{17,25}$ The most obvious STS combination is trabectedin in combination with doxorubicin. In a phase I, open-label study conducted at five sites evaluating 41 patients with soft-tissue sarcoma, doxorubicin was administered as a fifteen minute infusion in doses ranging from $50-75 \mathrm{mg} / \mathrm{m}^{2}$ followed by trabectedin in doses ranging from $0.9 \mathrm{mg} / \mathrm{m}^{2}$ to $1.3 \mathrm{~g} / \mathrm{m}^{2}$ as a three-hour IV infusion. The maximum tolerated dose (MTD) in this study given in three week cycles was trabectedin $1.1 \mathrm{mg} / \mathrm{m}^{2}$ with doxorubicin $60 \mathrm{mg} / \mathrm{m}^{2}$ with

Table I Evidence base included in the review

\begin{tabular}{lll}
\hline Category & \multicolumn{2}{l}{ Number of records } \\
\cline { 2 - 3 } & Full papers & Abstracts \\
\hline Initial search & 112 & 0 \\
Records excluded & 97 & 0 \\
Records included & 14 & 1 \\
Level I evidence & 0 & 0 \\
Level 2 evidence (RCT) & 0 & 0 \\
Level $\geq 3$ & 14 & 1 \\
Trials other than RCT & & \\
Pharmacokinetic studies & & \\
Pharmacodynamic studies & & 0 \\
Economic evidence & 0 & \\
\hline
\end{tabular}

Abbreviation: RCT, randomized, controlled trial. granulocyte-colony stimulating factor (G-CSF) support given significant myelosuppression. Although the primary goal of this study was not tumor response, as in the other phase I studies, there were partial responses (PR) observed in $5 / 41$ patients $(21 \%)$ and stable disease (SD) in 34/41 patients (83\%). ${ }^{26}$ Another phase I study evaluating the same duo of drugs evaluated 38 previously untreated STS and breast cancer patients with a dose of $60 \mathrm{mg} / \mathrm{m}^{2}$ of doxorubicin and trabectedin in doses escalating from $600 \mu \mathrm{g} / \mathrm{m}^{2}$ to $800 \mu \mathrm{g} / \mathrm{m}^{2}$ which was the MTD due to febrile neutropenia. Ten patients in this study achieved a PR, five with STS and five with breast cancer. The sarcoma histologies that responded were LMS, liposarcoma, carcinosarcoma, uterine adenosarcoma and malignant schwannoma. Toxicity was similar to that seen in the other phase I studies with severe but reversible hepatic toxicity, nausea and vomiting and fatigue. Noncumulative neutropenia occurred in all patients with the nadir occurring around day 15 and taking seven days to recover. ${ }^{17} \mathrm{~A}$ variation on the anthracycline theme was a phase I study combining pegylated liposomal doxorubicin (PLD) with trabectedin. In an open label study, 36 assessable patients, 16 of which were sarcoma (44\%) were treated with $30 \mathrm{mg} / \mathrm{m}^{2}$ of PLD and trabectedin infused over three hours at doses ranging from $0.4 \mathrm{mg} / \mathrm{m}^{2}$ to $1.3 \mathrm{mg} / \mathrm{m}^{2}$ repeated every 21 days. The MTD was $1.1 \mathrm{mg} / \mathrm{m}^{2}$ with similar elevations in transaminases and myelosuppression that had been seen in other phase I trials. Interestingly, fifteen patients on the trial achieved cumulative anthracycline doses of $300 \mathrm{mg} / \mathrm{m}^{2}$ (two with previous exposure). Repeated multiple gated acquisition scans or two-dimensional (2D) echocardiograms revealed decreased cardiac ejection fractions (left ventricular ejection fraction $[\mathrm{LVEF}] \geq 20 \%$ versus baseline) in six patients. As per the protocol, five of six patients continued on with trabectedin alone, and at the end of study, three patients had improvement in ejection fraction, and the other three did not have available studies to review. The overall response rate for the sarcoma patients was $12.5 \%$ with an additional six sarcoma patients (37.5\%) achieving disease stabilization. The histologic subtypes of the sarcoma patients were not mentioned in the published study results. ${ }^{27}$ Lastly, in a phase I trial of weekly trabectedin with gemcitabine in patients with advanced solid tumors, 15 patients received gemcitabine on days 1,8 , and 15 of a 28-day schedule followed by trabectedin with doses ranging between $0.3 \mathrm{mg} / \mathrm{m}^{2}$ and $0.58 \mathrm{mg} / \mathrm{m}^{2}$. Five patients in this study had STS. The study was terminated early due to an unacceptable frequency of adjustments to the weekly dosing schedule due to hepatic toxicity. There were no dose-limiting toxicities observed and 
no objective responses, although almost half of the patients $(47 \%)$ analyzed had stable disease after two cycles. ${ }^{28}$

\section{The phase II clinical experience in soft tissue sarcoma}

A total of 225 assessable patients were evaluated in four phase II clinical trials evaluating the efficacy of trabectedin in soft-tissue, gastrointestinal stromal tumor (GIST) and bone sarcoma patients. The largest of these studies was a multicenter, nonrandomized EORTC study evaluating one hundred and four patients with soft tissue and bone sarcoma from eight European institutions. Patients were stratified to three major disease groups; non-GIST patients with prior chemotherapy evaluated by WHO criteria, non-GIST patients without prior chemotherapy evaluated by WHO criteria and RECIST criteria, and GIST patients without prior therapy evaluated by WHO criteria. The GIST patients will be commented on below. Trabectedin was administered at a dose of $1.5 \mathrm{mg} / \mathrm{m}^{2}$ IV as a 24-hour continuous infusion every three weeks. The most commonly encountered side effects and toxicities were similar to those experienced in the phase I trials: nausea, vomiting, myelosuppression, and rise in liver transaminases. Forty-three patients (41\%) had LMS of various locations, $17.3 \%$ had synovial sarcoma, 9.6\% with liposarcoma, and $5.7 \%$ with "MFH". Ninety percent of patients had grade 2 or 3 sarcomas. Among the 99 treated patients, there were eight PR (objective regression rate of $8.1 \%$ ), 45 no change (40.5\%), and 39 with progressive disease $(39.4 \%)$. The median duration of response was 352 days (50 weeks). The responses were seen in LMS, synovial, liposarcoma, and MFH. The outcome was similar in patients who had received one or two previous chemotherapy lines and in patients having chemosensitive or chemoresistant sarcoma. ${ }^{29}$ The third group evaluated in the above trial, but reported separately were the GIST patients without any prior therapy. Twenty-eight patients with locally advanced and/or metastatic GIST with progressive disease were enrolled onto the EORTC study. No objective responses were seen, and $67 \%$ of patients experienced progressive disease after their first evaluation, while $33 \%$ experienced no change as their best response. This portion of the study was performed prior to the imatinib era for GIST, and the studies conclusion was that trabectedin could be added to the long list of ineffective drugs for GIST. ${ }^{30}$

Another phase II and pharmacokinetic study of trabectedin was performed in patients with STS refractory to chemotherapy. Thirty-six patients were enrolled on this study at three institutions, and again, the $1.5 \mathrm{mg} / \mathrm{m}^{2} 24$-hour infusion schedule was utilized. Objective responses were seen in three patients, with one complete response in a myxoid/round-cell liposarcoma patient and two partial responses, one in a dedifferentiated liposarcoma patient and the other in a LMS patient. These responses were durable for up to 20 months. Two minor responses were also seen with $43 \%$ and $47 \%$ tumor reduction, for an overall clinical benefit rate of $14 \%$ in two patients, one with a myxoid/round-cell liposarcoma and one with a fibrosarcoma. ${ }^{31}$

Additionally, a phase II study of trabectedin in advanced pretreated STS patients treated at four separate French institutions utilizing the $1.5 \mathrm{mg} / \mathrm{m}^{2}$ 24-hour infusion schedule every three weeks was performed. Two distinct groups were evaluated, one group had prior therapy with one or two single agents or one combination therapy, and the second group had prior therapy with three or more single agents or two or more combination therapies. Fifty-four patients were enrolled and all were assessable for efficacy. Two partial responses were seen $(3.7 \%)$ and four patients had minor responses (7.4\%). Furthermore, nine patients had stable disease for $>6$ months (17\%). Four of the responding patients had LMS, three of which were uterine, one patient had a uterine endometrial stromal sarcoma, and one patient had a head and neck fibrosarcoma. Of note, there were two deaths on this trial that were possibly attributable to trabectedin. Both patients developed acute renal failure with febrile neutropenia and rhabdomyolisis, although there was note of a protocol violation that may have led to the fatal outcome. ${ }^{21}$

Lastly, 36 chemotherapy-naïve patients were enrolled on a phase II trial utilizing the 24-hour continuous infusion schedule every 21 days. The predominant histologic subtype was LMS and liposarcoma and tumor bulk was $>5 \mathrm{~cm}$ in two thirds of patients and $>10 \mathrm{~cm}$ in $19 \%$ of patients. Approximately half of the patients had received prior radiation therapy, but only $11 \%$ had received prior chemotherapy. Six of the 35 assessable patients exhibited an objective response of $17.1 \%$. The responses, similar to other studies, occurred in myxoid/round cell sarcoma (three patients), LMS (one patient), fibrosarcoma (one patient), and synovial sarcoma (one patient). As expected, the most severe toxicities were primarily hematologic and hepatic. Although the study sample size was small, the outcome of this phase II trial concluded that trabectedin induced responses in $17 \%$ of study patients with a one year overall survival rate of $72 \% .^{32}$ These results rivaled those from other first-line studies using doxorubicin and ifosfamide. ${ }^{33-35}$

\section{Compassionate use trials}

There are two studies published to date that evaluated a total of 72 patients in compassionate use trials. The first 
study focused specifically on liposarcoma, given this histologic subtype responses seen in the other phase II trials. Fifty-one patients with advanced myxoid liposarcoma treated at five separate institutions in a compassionate use program were retrospectively reviewed. The drug was given either as a 24-hour continuous infusion or as the three-hour infusion every 21 days. RECIST criteria were utilized and after a median follow up of 14 months, two patients had achieved complete responses and 24 patients had partial responses providing an overall response rate of $51 \%$. The second study evaluated 21 patients at a single UK center, also treated on a compassionate use basis. All the patients had received prior anthracycline and 95\% had received ifosfamide. Partial responses were seen in three patients $(14 \%)$ and a further eight patients (38\%) achieved a durable stable disease for a median of 4.5 months. The responses were seen in a liposarcoma patient, a Ewing's sarcoma patient, and STS NOS.

\section{Resource utilization}

Trabectedin met approval in July of 2007 by the Committee for Medicinal Products for Human Use in Europe. The European Commission has authorized its use and it is commercially available in several countries in Europe and Japan where it is marketed for the treatment of STS in adults after failure of standard therapy. The approval dose is $1.5 \mathrm{mg} / \mathrm{m}^{2}$ as a 24-hour continuous infusion, once every three weeks. Pharma Mar, who markets trabectedin in Europe and Japan has started a phase III multicenter study of Yondelis ${ }^{\circledR}$ as first line therapy in patients with tumor translocation sarcomas. Trabectedin is currently not commercially available in the United States and Canada. It is currently available in several expanded access studies focusing on patients with persistent or recurrent STS who have exhausted other therapeutic options. Ortho Biotech Products, LP a subsidiary of Johnson \& Johnson will market trabectedin in North America. A registration dossier was submitted to the FDA in late 2008 for the treatment of refractory ovarian cancer and a decision of approval is expected to take place in 2009.

\section{Dosage, administration, and formulations}

The recommended dose, as it is approved in Europe, is $1.5 \mathrm{mg} / \mathrm{m}^{2}$ body surface area, administered as an IV infusion over 24 hours with a three week interval between cycles. Administration through a central venous catheter is suggested. All patients should receive $20 \mathrm{mg}$ of dexamethasone intravenously 30 minutes prior to trabectedin, not only as an anti-emetic, but also as a liver protectant.
Additional anti-emetics can be administered as needed. Oral pre-medication with dexamethasone administered 24 hours prior to trabectedin therapy, dramatically reduced myelosuppression and hepatotoxciity. ${ }^{36,37}$

Although grade 3 and 4 nausea and vomiting were observed in some patients, many of the well-known and debilitating side effects associated with doxorubicin and ifosfamide, were not observed, namely, cardiac and neurotoxicity. ${ }^{37}$

Unopened vials have a shelf life of 36 months. After reconstitution, chemical and physical stability has been demonstrated for 30 hours up to $25^{\circ} \mathrm{C}$. No incompatibilities have been observed between trabectedin and polyvinylchloride and polyethylene bags and tubing, and titanium implantable access systems. ${ }^{38}$

\section{Safety and toxicity}

As with other cytotoxic chemotherapeutics, the side effect profile can be extensive. Reversible myelosuppression was found to be one of the most common grade 3 and 4 toxicities in the phase I and II studies. This suppression appears to be dose dependent, with median nadir at approximately 14 days. Trabectedin neutropenia seems to be largely dependent on the intensity of the dose, but not the duration of infusion. ${ }^{39}$ Reversible increases in serum transaminases, bilirubin and alkaline phosphatase were also observed. The elevation generally took place $2-5$ days after trabectedin administration, reaching a maximum level between days 5-9. With the addition of dexamethasone, there is a hepatic protective effect as evaluated in a semi mechanistic pharmacokinetic/ pharmacodynamic model by Fetterly et al. ${ }^{40}$ Dexamethasone can also aid in the prevention of nausea and vomiting.

\section{Place in therapy}

The current best available evidence from several nonrandomized phase II trials, coupled with the compelling experience from several phase I studies suggest that trabectedin is a safe and effective therapeutic option in STS with specific efficacy in myxoid/round cell sarcoma, and LMS (Table 2). In a disease group as diverse as sarcoma, complicated by the lack of good therapeutic options in the second line setting, trabectedin has limited but compelling evidence to support its use in patients who have exhausted other therapeutic options. It remains to be seen if trabectedin will be approved in the US, either for ovarian cancer, or for STS. The small non randomized studies that have been performed thus far have shown that trabectedin is clearly not a home run when it comes to most STS subtypes; however, in isolated subsets of patients, like 
Table 2 Summary of the phase II response rates of trabectedin in advanced soft tissue sarcoma

\begin{tabular}{lllllll}
\hline Study & No. of patients & ORR (\%) & SD (\%) & CBR (\%) & Median TTP & Six months PFS \\
\hline Garcia-Carbonero et al $^{31}$ & 36 & 8.3 & NR & 14 & 1.7 months & $23 \%$ \\
Yovine et al $^{21}$ & 52 & 3.7 & 17 & 24 & 1.9 months & $24 \%$ \\
Le Cesne et al $^{29}$ & 99 & 8.1 & 40.5 & 53.6 & 105 days & $26 \%$ \\
Garcia-Carbonero et al $^{32}$ & 35 & 17.1 & NR & 20 & 16.5 months & $24.4 \%$ \\
\hline
\end{tabular}

Notes: CBR, clinical benefit response; NR, not reported; ORR, objective response rates; PFS, progression-free survival; SD, stable disease; TTP, time to progression.

myxoid/round cell liposarcoma, there is compelling evidence to suggest it is a viable treatment option. As compelling as this information is, evaluating this data in a randomized, prospective fashion, will substantiate this claim. As the finishing touches are being put on this article, trabectedin is being approved in Italy, and should be available to Italian sarcoma patients in the ensuing weeks. This adds Italy, to the roster of other countries, including Russia, where trabectedin, under the trade name Yondelis ${ }^{\circledR}$, is available. Perhaps the phase III study, which will evaluate the safety and effectiveness of trabectedin versus doxorubicin-based chemotherapy in patients with translocation-related sarcomas, will provide sufficient evidence for the US Food and Drug Administration to approve this drug in soft-tissue sarcoma for those patients who have exhausted other therapeutic options.

\section{Acknowledgments}

Dr Thornton has no conflict of interest to report for this publication.

\section{References}

1. Jemal A, Siegel R, Ward E, Murray T, Xu J, Thun MJ. Cancer statistics, 2007. CA Cancer J Clin. 2007;57(1):43-66.

2. Lawrence W Jr, Donegan WL, Natarajan N, Mettlin C, Beart R, Winchester D. Adult soft tissue sarcomas. A pattern of care survey of the American College of Surgeons. Ann Surg. 1987;205(4):349-359.

3. Fletcher CD. The evolving classification of soft tissue tumours: an update based on the new WHO classification. Histopathology. 2006;48(1):3-12.

4. Borden EC, Baker LH, Bell RS, et al. Soft tissue sarcomas of adults: state of the translational science. Clin Cancer Res. 2003;9(6):1941-1956.

5. Wolf PS, Flum DR, Tanas MR, Rubin BP, Mann GN. Epithelioid sarcoma: the University of Washington experience. Am J Surg. 2008;196(3):407-412.

6. Brennan MF, Harrison CE. Sarcomas of soft tissue and bone. In: DeVita VT, Lawrence TS, Rosenberg SA, DePinho RA, Weinberg RA, editors. Cancer: Principles and Practice of Oncology. 5th edition. Philadelphia, PA: Lippincott Williams \& Wilkinson; 1997.

7. Morton DL, Tepper AK. Bone and soft tissue sarcomas. In: Holland JF, Frei E, Bast RC, Morton DL, editors. Cancer Medicine. Philadelphia, PA: Lippincott Williams \& Wilkins; 1997.

8. Blay JY, van Glabbeke M, Verweij J, et al. Advanced soft-tissue sarcoma: a disease that is potentially curable for a subset of patients treated with chemotherapy. Eur J Cancer. 2003;39(1):64-69.

9. Koea JB, Leung D, Lewis JJ, Brennan MF. Histopathologic type: an independent prognostic factor in primary soft tissue sarcoma of the extremity? Ann Surg Oncol. 2003;10(4):432-440.
10. Baker LH, Frank J, Fine G, et al. Combination chemotherapy using adriamycin, DTIC, cyclophosphamide, and actinomycin D for advanced soft tissue sarcomas: a randomized comparative trial. A phase III, Southwest Oncology Group Study (7613). J Clin Oncol. 1987;5(6): 851-861.

11. Maki RG, Wathen JK, Patel SR, et al. Randomized phase II study of gemcitabine and docetaxel compared with gemcitabine alone in patients with metastatic soft tissue sarcomas. JClin Oncol. 2007;25(19): 2755-2763.

12. Pervaiz N, Colterjohn N, Farrokhyar F, Tozer R, Figueredo A, Ghert M. A systematic meta-analysis of randomized controlled trials of adjuvant chemotherapy for localized resectable soft-tissue sarcoma. Cancer. 2008;113(3):573-581.

13. Judson I, Radford JA, Harris M, et al. Randomised phase II trial of pegylated liposomal doxorubicin (DOXIL/CAELYX) versus doxorubicin in the treatment of advanced or metastatic soft tissue sarcoma: a study by the EORTC Soft Tissue and Bone Sarcoma Group. Eur $J$ Cancer. 2001;37(7):870-877.

14. Skubitz KM. Phase II trial of pegylated-liposomal doxorubicin (Doxil) in sarcoma. Cancer Invest. 2003;21(2):167-176.

15. Casper ES, Waltzman RJ, Schwartz GK, et al. Phase II trial of paclitaxel in patients with soft-tissue sarcoma. Cancer Invest. 1998;16(7):442-446.

16. Guan Y, Sakai R, Rinehart KL, Wang AH. Molecular and crystal structures of ecteinascidins: potent antitumor compounds from the Caribbean tunicate Ecteinascidia turbinata. J Biomol Struct Dyn. 1993;10(5):793-818.

17. D'Incalci M, Colombo T, Ubezio P, et al. The combination of yondelis and cisplatin is synergistic against human tumor xenografts. Eur $J$ Cancer. 2003;39(13):1920-1926.

18. Pommier Y, Kohlhagen G, Bailly C, Waring M, Mazumder A, Kohn KW. DNA sequence- and structure-selective alkylation of guanine N2 in the DNA minor groove by ecteinascidin 743, a potent antitumor compound from the Caribbean tunicate Ecteinascidia turbinata. Biochemistry. 1996;35(41):13303-13309.

19. Gajate C, An F, Mollinedo F. Differential cytostatic and apoptotic effects of ecteinascidin-743 in cancer cells. Transcription-dependent cell cycle arrest and transcription-independent JNK and mitochondrial mediated apoptosis. J Biol Chem. 2002;277(44):41580-41589.

20. Delaloge S, Yovine A, Taamma A, et al. Ecteinascidin-743: a marinederived compound in advanced, pretreated sarcoma patients - preliminary evidence of activity. J Clin Oncol. 2001;19(5):1248-1255.

21. Yovine A, Riofrio M, Blay JY, et al. Phase II study of ecteinascidin743 in advanced pretreated soft tissue sarcoma patients. J Clin Oncol. 2004;22(5):890-899.

22. Lau L, Supko JG, Blaney S, et al. A phase I and pharmacokinetic study of ecteinascidin-743 (Yondelis) in children with refractory solid tumors. A Children's Oncology Group study. Clin Cancer Res. 2005; 11(2 Pt 1):672-677.

23. Twelves C, Hoekman K, Bowman A, et al. Phase I and pharmacokinetic study of Yondelis (Ecteinascidin-743; ET-743) administered as an infusion over $1 \mathrm{~h}$ or $3 \mathrm{~h}$ every 21 days in patients with solid tumours. Eur J Cancer. 2003;39(13):1842-1851.

24. Villalona-Calero MA, Eckhardt SG, Weiss G, et al. A phase I and pharmacokinetic study of ecteinascidin- 743 on a daily x 5 schedule in patients with solid malignancies. Clin Cancer Res. 2002;8(1):75-85. 
25. Takahashi N, Li WW, Banerjee D, Scotto KW, Bertino JR. Sequence-dependent enhancement of cytotoxicity produced by ecteinascidin 743 (ET-743) with doxorubicin or paclitaxel in soft tissue sarcoma cells. Clin Cancer Res. 2001;7(10):3251-3257.

26. Blay JY, von Mehren M, Samuels BL, et al. Phase I combination study of trabectedin and doxorubicin in patients with soft-tissue sarcoma. Clin Cancer Res. 2008;14(20):6656-6662.

27. Demetri GD, von Mehren M, Blanke CD, et al. Efficacy and safety of imatinib mesylate in advanced gastrointestinal stromal tumors. $N$ Engl $J$ Med. 2002;347(7):472-480.

28. Messersmith WA, Jimeno A, Ettinger D, et al. Phase I trial of weekly trabectedin (ET-743) and gemcitabine in patients with advanced solid tumors. Cancer Chemother Pharmacol. 2008;63(1):181-188.

29. Le Cesne A, Blay JY, Judson I, et al. Phase II study of ET-743 in advanced soft tissue sarcomas: a European Organisation for the Research and Treatment of Cancer (EORTC) soft tissue and bone sarcoma group trial. J Clin Oncol. 2005;23(3):576-584.

30. Blay JY, Le Cesne A, Verweij J, et al. A phase II study of ET-743/ trabectedin ('Yondelis') for patients with advanced gastrointestinal stromal tumours. Eur J Cancer. 2004;40(9):1327-1331.

31. Garcia-Carbonero R, Supko JG, Manola J, et al. Phase II and pharmacokinetic study of ecteinascidin 743 in patients with progressive sarcomas of soft tissues refractory to chemotherapy. J Clin Oncol. 2004;22(8):1480-1490.

32. Garcia-Carbonero R, Supko JG, Maki RG, et al. Ecteinascidin-743 (ET-743) for chemotherapy-naive patients with advanced soft tissue sarcomas: multicenter phase II and pharmacokinetic study. J Clin Oncol. 2005;23(24):5484-5492.
33. Bramwell VH, Mouridsen HT, Santoro A, et al. Cyclophosphamide versus ifosfamide: final report of a randomized phase II trial in adult soft tissue sarcomas. Eur J Cancer. Clin Oncol. 1987;23(3):311-321.

34. Edmonson JH, Ryan LM, Blum RH, et al. Randomized comparison of doxorubicin alone versus ifosfamide plus doxorubicin or mitomycin, doxorubicin, and cisplatin against advanced soft tissue sarcomas. J Clin Oncol. 1993;11(7):1269-1275.

35. Santoro A, Tursz T, Mouridsen H, et al. Doxorubicin versus CYVADIC versus doxorubicin plus ifosfamide in first-line treatment of advanced soft tissue sarcomas: a randomized study of the European Organization for Research and Treatment of Cancer Soft Tissue and Bone Sarcoma Group. J Clin Oncol. 1995;13(7):1537-1545.

36. Grosso F, Dileo P, Sanfilippo R, et al. Steroid premedication markedly reduces liver and bone marrow toxicity of trabectedin in advanced sarcoma. Eur J Cancer. 2006;42(10):1484-1490.

37. Schoffski P, Wolter P, Clement P, et al. Trabectedin (ET-743): evaluation of its use in advanced soft-tissue sarcoma. Future Oncol. 2007;3(4):381-392.

38. Medicines.org.uk. Pharma Mar SA. Available from: http://www.emc. medicines.org.uk/. Accessed March 31st, 2008.

39. Hing J, Perez-Ruixo JJ, Stuyckens K, Soto-Matos A, Lopez-Lazaro L, Zannikos P. Mechanism-based pharmacokinetic/pharmacodynamic meta-analysis of trabectedin (ET-743, Yondelis) induced neutropenia. Clin Pharmacol Ther. 2008;83(1):130-143.

40. Fetterly GJ, Owen JS, Stuyckens K, et al. Semimechanistic pharmacokinetic/pharmacodynamic model for hepatoprotective effect of dexamethasone on transient transaminitis after trabectedin (ET-743) treatment. Cancer Chemother Pharmacol. 2008;62(1):135-147.
Core Evidence

\section{Publish your work in this journal}

Core Evidence is an international, peer-reviewed open-access journal evaluating the evidence underlying the potential place in therapy of drugs throughout their development lifecycle from preclinical to postlaunch. The focus of each review is to evaluate the case for a new drug or class in outcome terms in specific indications and patient

\section{Dovepress}

groups. The manuscript management system is completely online and includes a very quick and fair peer-review system, which is all easy to use. Visit http://www.dovepress.com/testimonials.php to read real quotes from published authors. 